\title{
Seismic Reliability Analysis of Long-Span Cable-stayed Bridges
}

\author{
Wu Fangwen", Yang Caofang, Xue Chengfeng and Ji Zhengdi
}

School of Highway, Chang'an University, Xi'an, Shaanxi, 710064, China

\begin{abstract}
Earthquake motion is a random process, and thus, analyzing the seismic responses and dynamic reliability of cable-stayed bridges based on the random vibration theory is important. In this paper, dynamic reliability is investigated under earthquake loads by applying the stochastic vibration theory to the Sutong Yangtze River Highway Bridge. The response statistics are obtained from random vibration analyses, and the dynamic reliability of the normal stress of several key cross sections in the bridge is analyzed using the first-order second-moment method and the first-passage failure theory. The dynamic reliability analysis shows that the reliability index changes with girder section location and meets the design requirements. The analysis shows that the Sutong Bridge has adequate earthquake resistance ability. The structure's earthquake resistance is appraised to provide an important theoretical reference for improving the seismic resistance design methods.
\end{abstract}

Keywords: Cable-stayed bridge, dynamic reliability, earthquake motion model, first passage failure theory, stochastic vibration.

\section{INTRODUCTION}

Dynamic reliability theory is a recently developed branch of random vibration theory [1-5]. Earthquakes have a strong random feature, and thus, a reasonable way to analyze the dynamic reliability is to conduct an analysis based on the random vibration theory. In analyzing earthquake reliability, Lupoil, Franchinl, and Cornell applied seismic risk assessment methods of steel probabilistics to a reinforced concrete bridge system by considering the earthquake load excitation and parameter uncertainty [6]. Ou Jin-ping and Wang Guang-yuan proposed a failure criterion based on the fuzzy dynamic reliability analysis of the seismic method that determines ambiguity in the level of structural damage [7]. In this study, fuzzy boundaries were proposed as outer boundaries, and the limit theory and point process method were used to indicate that the derived structural response did not exceed the probability of the fuzzy boundaries. ZhaoYan studied the dynamic reliability problem of large-span bridge structures and analyzed the stochastic seismic response by considering random parameters and the random perturbation method [8]. Liu presented an analysis of the spatial effect of earthquake ground motion by using random vibration pseudo excitation method and computing the structural system reliability [9]. A number of studies on dynamic reliability have been conducted by local and foreign researchers. However, few studies have focused on the dynamic reliability of cablestayed bridges during earthquake activities. Therefore, studying the reliability of cable-stayed structures has important theoretical significance because such studies can contribute to the development of the scientific basis for the bridge reliability theory.

*Address correspondence to this author at the School of Highway, Chang'an University, Xi'an, Shanxi, 710064, P.R. China; Tel: +86 2982338970 ; E-mail: iBridge2014@163.com
This paper applied the random vibration theory to analyze the dynamic reliability of the Sutong Yangtze River cable-stayed bridge under earthquake loads. The structure dynamic responses of random earthquake loads were first calculated and the square value responses obtained. The responses imply that the structure is in a stationary, normal random process with underground motion when the mean is zero. The reliability index of several key cross sections was calculated using the first-order second-moment (FOSM) method and first-passage failure theory for the Sutong cablestayed bridge. The FOSM method adopted the maximum seismic dynamic response as the random variable to calculate the structure reliability, whereas the first-passage failure theory treats seismic response directly as a stochastic process.

\section{FIRST-PASSAGE FAILURE THEORY}

The response of a single structure can be observed through the first-passage failure criterion $[10,11]$. The dynamic reliability structure refers to response time that is not within the specified period and beyond the limits of probability. Calculating the probability can be very difficult because no exact solution is available, although several assumptions similar to the approximate solution can be assumed as random responses, which are beyond the boundaries of the cross-compliance with a process.

The first beyond failure mechanism is based on the dynamic reliability structure analysis of a random process $x(t)$ and boundaries $x=b$ based on cross statistics. At time [0, $\mathrm{T}]$, the random process $x(t)$ to the positive and negative slopes, with boundaries $b$ as the crossing number expected value, can be expressed as:

$$
N_{b}(t)=\int_{0}^{T} v_{b}(t) d t=\int_{0}^{T} \int_{-\infty}^{+\infty}|\dot{x}(t)| f_{x \dot{x}}(b, \dot{x}, t) d t d x,
$$


where $v_{b}(t)$ is the cross number of unit time and $f_{x \dot{x}}(\mathrm{~b}, \dot{x}, t)$ is the joint probability density function of $x(t)$ and $\dot{x}(t)$. When $x(t)$ is a zero-mean stationary.

Gaussian process. $x(t)$ and $\dot{x}(t)$ are not related, and $t$, $x(t)$ and $\dot{x}(t)$ are not related, and $t$,

$f_{x \dot{x}}(b, \dot{x}, t)=\frac{1}{2 \pi \sigma_{x} \sigma_{\dot{x}}} \exp \left(-\frac{b^{2}}{2 \sigma_{x}^{2}}-\frac{b^{2}}{2 \sigma_{\dot{x}}^{2}}\right)$.

Similarly, cross rate $v_{b}(t)$ is independent of time, as given by:

$v_{b}=\frac{\sigma_{\dot{x}}}{\pi \sigma_{x}} \exp \left(-\frac{b^{2}}{2 \sigma_{x}^{2}}\right)$.

In the past studies, the first super-system dynamic reliability analysis, which is the most widely used method, was calculated as the Poisson assumption of power over the reliability of calculations. The assumption of $x(t)$ time $[0, \mathrm{~T}]$ with boundary $b$ in the limits of the cross followed a Poisson distribution. Therefore, dynamic reliability can be considered as the stochastic process $x(t)$ in time [0, T] within boundary $b$, which limits the cross with the probability of the number of zero instances. For both sides, the D boundaries can be derived as follows:

$$
\begin{aligned}
& P\left(\max x(t) \leq b_{1} \cap \min x(t) \geq-b_{2}, \quad 0<t \leq T\right) \\
& \quad=\exp \left[-\int_{0}^{T} v_{b_{1}}^{+}(t) d t\right] \cdot \exp \left[-\int_{0}^{T} v_{b_{2}}^{-}(t) d t\right] . \\
& \quad=\exp \left\{-\int_{0}^{T}\left[v_{b_{1}}^{+}+v_{b_{2}}^{-}\right] d t\right\}
\end{aligned}
$$

The bilateral symmetry for both $\mathrm{D}$ boundaries can be achieved by providing the structural response as the zeromean stationary Gauss process, with the power reliability as follows:

$P_{s}(b,-b)=\exp \left[-\frac{\sigma_{\dot{x}} T}{\pi \sigma_{x}} \exp \left(-\frac{b^{2}}{2 \sigma_{x}^{2}}\right)\right]$.

The results are accurate for stationary reaction state structure response when $b \rightarrow \infty$. However, the calculation will have errors when $b$ is not too large. Thus, the main band is conservative (the calculation of reliability is low), and the errors are generated mainly by Poisson assumptions. Lin proposed that for narrow-band processes (e.g., a small damped linear system when the natural frequency is greater than the random fatigue loads within an excellent response time), the Poisson process is untenable. Thus, narrow-band processes cannot be considered independent of each cross event. The narrow-band waveform is close to the slow variation in the amplitude of the sine wave and thus, such wave occurs in a cycle of events beyond the boundary. In the next cycle, the probability of such recurrence beyond the boundaries is greater than the cross time tendency to occur in the emergence groups. However, with a high boundary, a small probability of boundary crossing remains regardless of whether the process of structural response is broad-band or narrow-band. The cross is a rare event; hence, the Poisson distribution assumption in such a case is acceptable. Vanmarke proposed significant improvements on the Poisson process, with the idea of crossing the number for the Markov process of assumptions, and creating the following correction formula:

$$
\begin{aligned}
P_{s}(-b, b, T) & =\exp \left[-\frac{\sigma_{\dot{x}} T}{\pi \sigma_{x}} \exp \left(-\frac{b^{2}}{2 \sigma_{x}^{2}}\right)\right] \\
& {\left[\frac{1-\exp \left(-\sqrt{\pi / 2} q^{1+a} \frac{b}{\sigma_{x}}\right)}{1-\exp \left(-\frac{b^{2}}{2 \sigma_{x}^{2}}\right)}\right], }
\end{aligned}
$$

where $q$ represents the spectral parameters.

$$
\begin{gathered}
q=\sqrt{1-\frac{\alpha_{1}^{2}}{\alpha_{0} \alpha_{2}}} \\
\alpha_{i}=\int_{0}^{\infty} \omega^{i} S_{x}(\omega) d \omega
\end{gathered}
$$

In the equation above, $a$ is an empirical parameter and the desirable value is $a=0.2$.

First-order second-moment method

The reliability index can be calculated using the FOSM method that considers the actual distribution type of random variables. The non-normal variables are converted into equivalent normal variables using the equivalent normalization approach. The linearization point is not selected on the mean value, but rather along the failure boundary, which corresponds to the structure failure probability. The seismic reliability index and failure probability are calculated using the FOSM method, with steps shown in Fig. (1). Based on the stress failure model of the main beam in the normal limit state, the limit state equation is given by

$$
\begin{aligned}
Z & =R-S \\
& =\sigma_{b}-\sigma_{G}-\sigma_{L}-\sigma_{E},
\end{aligned}
$$

where $\sigma$ is the girder ultimate strength, lognormal distribution; $\sigma_{G}$ is the static stress, normal distribution; $\sigma_{L}$ is the live load stress, extreme value distribution of type I; and $\sigma_{E}$ is the random earthquake stress, extreme value type I distribution.

When $Z>0$, resistance $R$ is greater than load effect $S$ and the structure is in a safe condition. When $Z<0$, resistance $R$ is less than load effect $\mathrm{S}$ and the structure is in a state of failure. When $\mathrm{R}=0$, resistance $\mathrm{R}$ is equal to load effect $\mathrm{S}$ and the structure is in a limited state.

\section{Engineering Application}

\section{(1) Project Introduction}

The Sutong Bridge crosses the Yangtze River approximately $100 \mathrm{~km}$ upstream from Shanghai, China and connects the cities of Suzhou and Nantong, which are located on the southern and northern banks, respectively. The bridge is a seven-span double-pylon and double-cable plane steel box girder cable-stayed bridge, with a span arrangement of $100+$ $100+300+1088+300+100+100=2088 \mathrm{~m}$, as shown in Fig. (2). The Sutong Bridge is the second longest cable- 

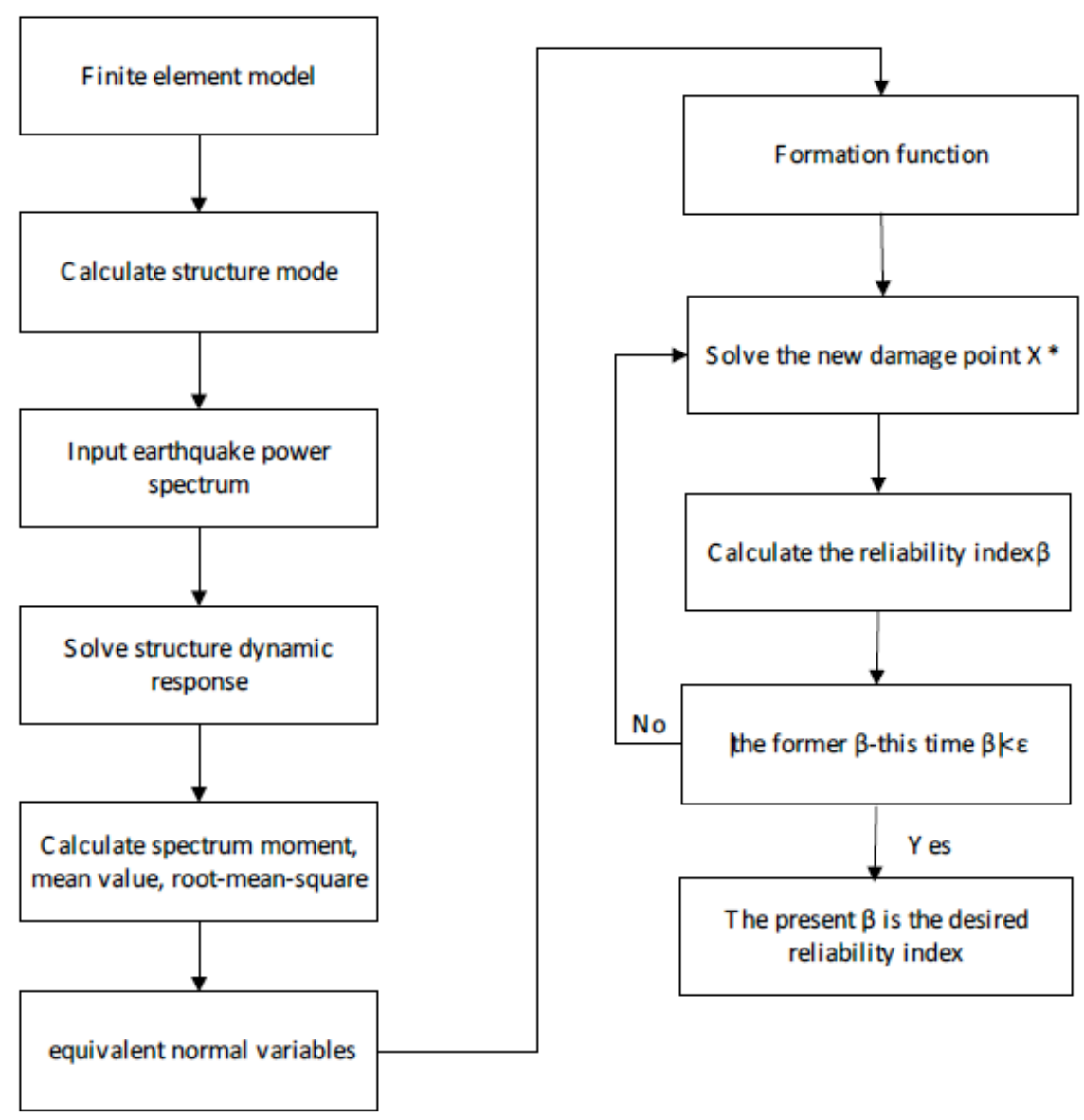

Fig. (1). Seismic reliability based on FOSM method.

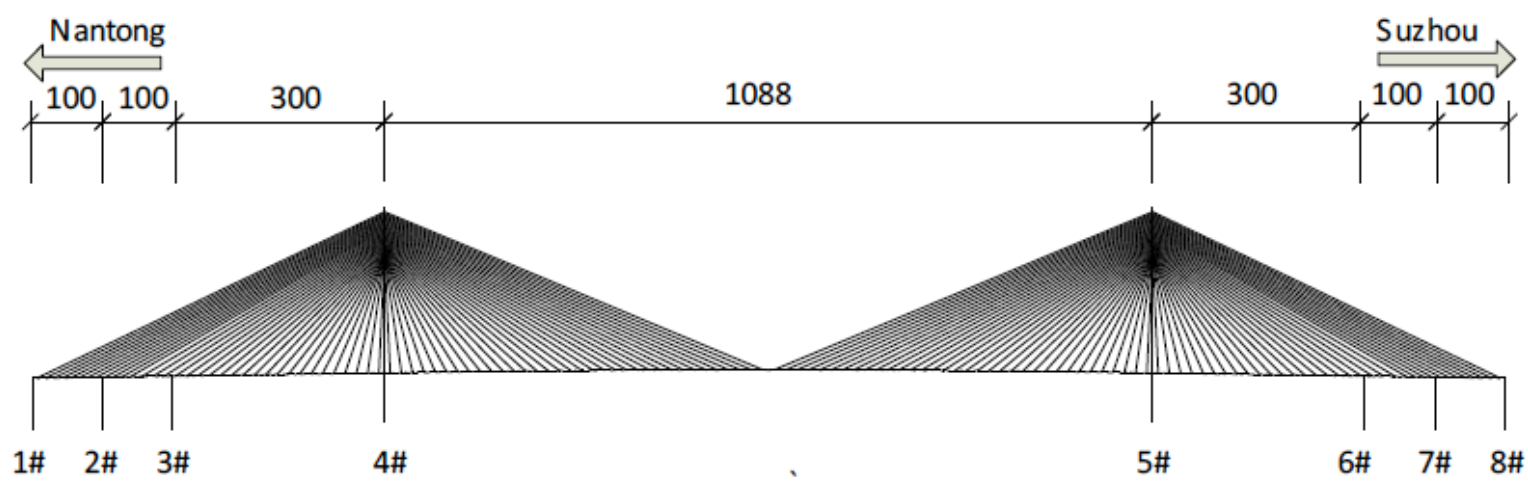

Fig. (2). Layout of the Sutong Yangtze river highway bridge.

stayed bridge in the world, and holds a record-breaking construction in the history of bridge building [12].

(2) Earthquake Simulation

The spatial earthquake model should reflect the earthquake characteristics as closely as possible. In general, the auto-power spectrum of each point is known, and the cross power spectrum can be represented as follows:

$S_{j k}=\sqrt{S_{j j}(\omega) S_{k k}(\omega)} \rho_{j k}(d, \omega) e^{i \omega \frac{d}{V_{a}(\omega)}}$ where $S_{i j}(\omega)$ and $S_{k k}(\omega)$ represent the auto-power spectrum of points $\mathrm{j}$ and $\mathrm{k}$, respectively; $\rho_{j k}(d, \omega)$ represents the coherence function of points $\mathrm{j}$ and $\mathrm{k}$ and reflects the related degree of the two points. $d$ refers to the distance between the two points along the earthquake propagation direction. In this paper, the Qutiejun-Wangjunjie coherence function model is adopted as follows:

$\left|\rho_{k l}\left(\omega, d_{k l}\right)\right|=\exp \left[-a(\omega) d_{k l}^{b(\omega)}\right]$,

where 


$$
\begin{aligned}
& a(\omega)=a_{1} \omega^{2}+a_{2}, b(\omega)=b_{1} \omega+b_{2}, a_{1}=0.00001678, \\
& a_{2}=0.001219, b_{1}=-0.0055, b_{2}=0.7674 .
\end{aligned}
$$

The earthquake wave $V_{a}(\omega)$ is one parameter of the earthquake ground spatial variation and its expression is as follows:

$$
V_{a}(\omega)=3344+1095 \ln (\omega / 2 \pi)
$$

Since Kanai-Tajimi, a Japanese researcher, proposed the white noise random earthquake ground power spectrum model in 1957, a number of researchers have improved on the model. The Du Xiuli-Chen HouQun model is used in this paper and its function is as follows:

$$
S_{A}(\omega)=\frac{1+4 \xi_{g}^{2} \frac{\omega^{2}}{\omega_{g}^{2}}}{\left(1-\frac{\omega^{2}}{\omega_{g}^{2}}\right)^{2}+4 \xi_{g}^{2} \frac{\omega^{2}}{\omega_{g}^{2}}} \cdot \frac{1}{1+(D \omega)^{2}} \cdot \frac{\omega^{4} \bullet S_{0}}{\left(\omega^{2}+\omega_{0}^{2}\right)},
$$

where $1 /\left(1+(D \omega)^{2}\right)$ and $\omega^{4} /\left(\omega^{2}+\omega_{0}^{2}\right)^{2}$ represent the low-pass and high-pass filters, respectively. $\omega_{0} \approx 1.83$ is the low corner frequency and $D$ equals $1 / 28 \pi$, which relates to the earthquake center. $\omega_{g}$ and $\xi_{g}$ represent the predominant frequency and damping ratio of the earthquake field soil, respectively.

The Sutong cable-stayed bridge is located in the soft field and is resistant to an intensity 7 earthquake for a 100year design life. The site type is grade III. According to the Du Xiuli-Chen HouQun model, the parameters of the model are as follows: $S_{0}=17.26 \mathrm{~cm}^{2} / \mathrm{s}^{3}, D=0.0114, \omega_{0}=1.83$, $\omega_{g}=13.03, \xi_{g}=0.97, T_{g}=13.66$. The acceleration power spectrum is shown in Fig. (3).

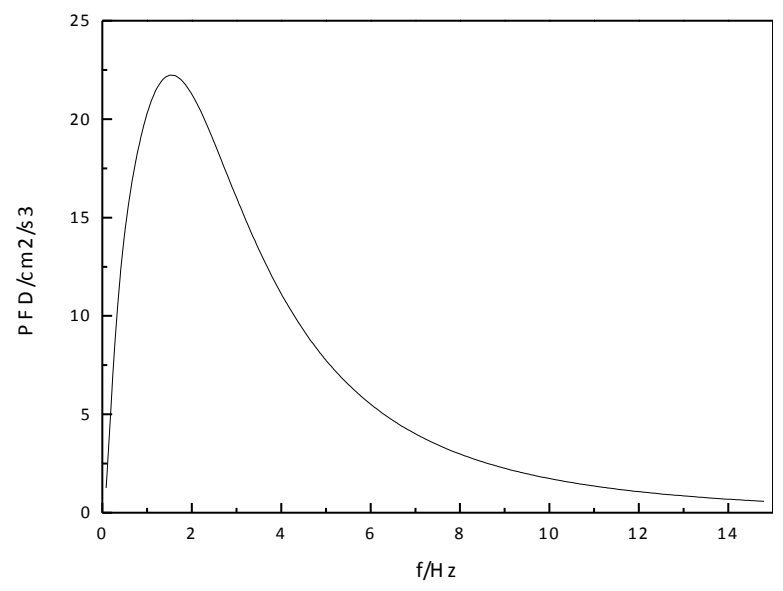

Fig. (3). Power spectrum curve of seismic acceleration.

\section{(3) Random earthquake response}

The FOSM method for solving seismic reliability is employed to calculate the maximum values of the random response. The quantitative estimates of the seismic response on the structure can be obtained using the variance and spectrum of the structure response, and the maximum mean and root mean square (RMS) values of the structure's random seismic response can be calculated. The mean and RMS val- ues of the bending moment and axial force are shown in Fig. (4).

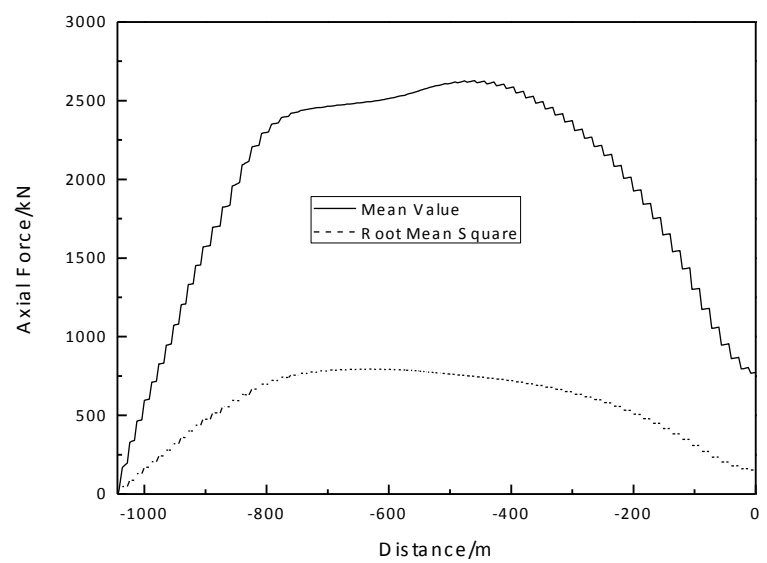

(a) Bending moment

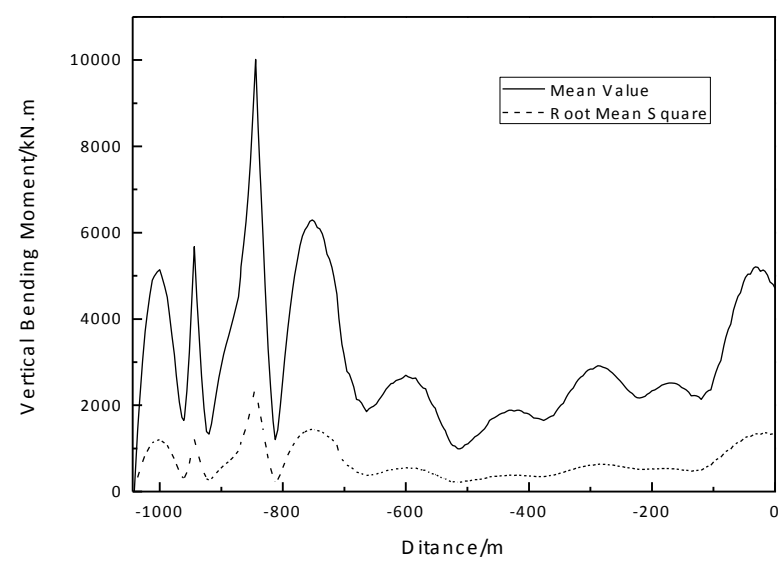

(b) Axial force

Fig. (4). Results of stochastic earthquake response (Half Bridge).

(4) Static analysis

Fig. (5) shows the stresses of the girder, which can be observed through the finite element analysis of the Sutong Bridge segment. The girder maximum compressive stress was $99.46 \mathrm{MPa}$ in the completed stage. The maximum compressive stress of the girder is $50 \mathrm{MPa}$ under the vehicle load, as shown in Fig. (6).

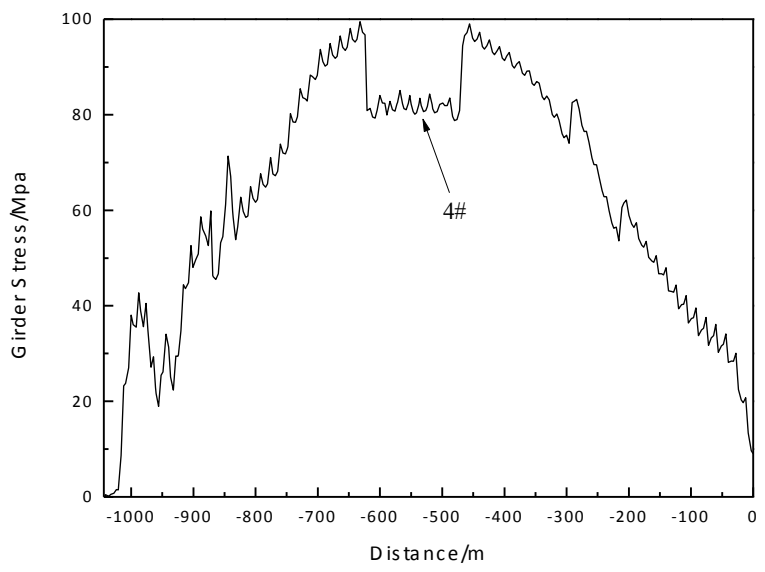

Fig. (5). Girder stress of static analysis (Half bridge). 


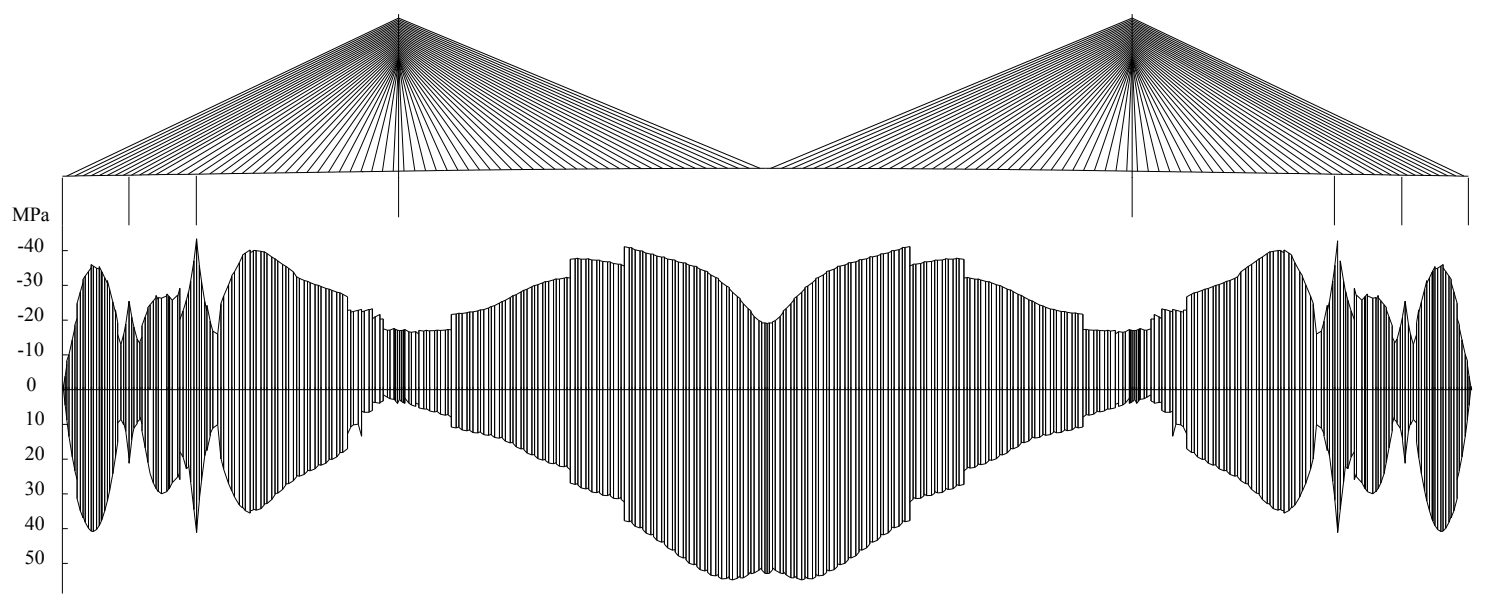

Fig. (6). Girder stress under vehicle load.

Table 1. Statistical parameters of variable.

\begin{tabular}{|c|c|c|c|c|}
\hline Key Section & Position & \multicolumn{3}{|c|}{ Mean Value/MPa } \\
\hline 2 & 2 piers & 34.05 & 34.69 & 14.18 \\
\hline 3 & 2, 3 piers mid-span & 49.60 & 43.65 & 12.63 \\
\hline 5 & 3,4 piers mid-span & 93.70 & 29.65 & 11.35 \\
\hline 6 & tower & 80.10 & 23.94 & 7.89 \\
\hline 7 & 1/8 mid-span & 94.24 & 33.98 & 10.08 \\
\hline
\end{tabular}

Table 2. Reliability index of girder.

\begin{tabular}{|c|c|c|c|}
\hline \multirow{2}{*}{ Key Section } & \multirow{2}{*}{ Position } & FoSM & \multicolumn{2}{|c|}{ Feliability index $\beta$} \\
\cline { 2 - 4 } & & 5.82 & 6.14 \\
\hline \hline 1 & 1,2 piers mid-span & 5.75 & 6.02 \\
\hline 2 & 2 piers & 5.36 & 5.82 \\
\hline 3 & 2,3 piers mid-span & 5.12 & 5.63 \\
\hline 4 & 3 piers & 5.28 & 5.50 \\
\hline 6 & 3,4 piers mid-span & 5.58 & 6.06 \\
\hline 7 & tower & 5.08 & 5.32 \\
\hline 9 & $1 / 8$ mid-span & 5.21 & 5.49 \\
\hline 10 & $1 / 4$ mid-span & 5.16 & 5.51 \\
\hline
\end{tabular}




\section{(5) Results}

According to the Steel Structures Design Code of China, the strength coefficient variation of the steel box girder is 0.1 with a normal distribution [12]. The $\sigma_{G}, \sigma_{L}$, and $\sigma_{E}$ coefficient variations are $0.1,0.2$, and 0.22 , respectively. The mean values of girder stress in several key cross sections are shown in Table $\mathbf{1}$.

The first passage failure criterion and the FSOM method indicate that the reliability index of the key sections for Sutong Bridge can withstand an intensity 7 earthquake, as shown in Table 2.

The table shows that the bridge is in a safe state under various loads, including earthquake loads. Different locations have varying reliability indices. The reliability of two piers is greater than that of three piers, and the reliability of the tower at the main beam reached 5.58. The maximum value of the reliability index is 6.06 at the half main span. The dead load stress accounted for the larger ratio in the total stress, and the trend of girder reliability was closer to the variation trend of the dead load stress. Thus, the design of the Sutong Bridge girder is reasonable. The trend of reliability associated with the girder cross section location can contribute to the optimization of the girder design according to the reliability index values. The methods for computing the dynamic reliability index differ, but the results of the analysis were close and the maximum difference was only about $8 \%$.

The dynamic reliability analysis showed that the reliability index changed with the girder section location and met the design requirements, proving that the Sutong Bridge has adequate earthquake resistance ability.

\section{CONCLUSION}

By conducting a reliability analysis of the Sutong cablestayed bridge, an in-depth qualitative understanding of the structure is obtained. Determining the reliability of the bridge's key parts will enable further integration of the results into the optimization of cable-stayed bridge design. The results of the analysis can also play an important role in improving the large-span cable-stayed bridge design, structural safety and durability assessments, remaining life prediction of existing bridges, risk assessment, and decision making. The primary conclusions are as follows. (1) The maximum response reliability index of the Sutong Bridge under random earthquake load is calculated using the FOSM method, and the results indicated that the Sutong Bridge structure can safely resist an intensity 7 earthquake. (2) The results ob- tained in the reliability analysis of the Sutong Bridge through first passage failure criterion are similar to that obtained using the FSOM method. Despite the variations in the computing theory of the reliability index in the two methods, the results had a maximum difference of only about $8 \%$.

\section{CONFLICT OF INTEREST}

The authors confirm that this article content has no conflict of interest.

\section{ACKNOWLEDGEMENTS}

The work was supported by the National Natural Science Funds for Young Scholars (No. 51408040) and the Fundamental Research Funds for Central Universities (No. 2013G1211012).

\section{REFERENCES}

[1] G. Wang, G. Cheng, Z. Shao, H. Chen, "Most Superior Intensity and Reliability of Resistance Earthquake Structure," Beijing: Science Press Co., Ltd, 1999

[2] J. Shen, X. Zhou, X. Gao, J. Liu, "Resistance Earthquake Engineering," China Building Industry Press Co., Ltd, 2000

[3] F. Hong, J. Jiang, Y. Li, "Power Spectral Models of Earthquake Ground Motions and Evaluation of it's parameters," Earthquake Engineering and Engineering Vibration, vo1. 14, no. 2, pp. 46-51. 1994.

[4] S. Shang, D. Li, Y. Du, "Response Analy-sis and Dynamic Reliability Calculation for Random Seismic of Ground Soil," Earthquake Resistant Engineering and Retrofitting, vol. 29, no. 1, pp. 26-30, 2007.

[5] B. Chen, L. Zhao, S. Chen, "Anti-seismic Reliability Analysis of the High-pier Long-Span Continuous Rigid Frame Railway Bridge," Journal of the China Railway Society, vol. 30, no. 2, pp. 113-117, 2008.

[6] A. Lupoil, R. Franchinl, M. Schotanus, "Seismic Risk Evaluation of RC Bride Structure," Earthquake Engineering and Structural Dynamics, vol. 32, no. 8, pp. 1275-1290, 2003.

[7] J. Ou, G. Wang, "Structure Random Vibration," Beijing: Higher Education Press Co., Ltd, 1998.

[8] Y. Zhao, "On linear/nonlinear Seismic Analysis Methods of Bridges," DaLian: Dalian University of Technology, 2003

[9] H. Liu, Y. Zhao, "Seismic Reliability of Long-Span Bridges under Multi-Support Excitations," Journal of Huazhong University of Science and Technology (Urban Science Edition), vol. 25, no. 3, pp. 113-120, 2008.

[10] G. Li, H. Cao, Q. Li, D. Huo, "Structure Dynamic Reliability Theory and Application," Beijing: Earthquake Press Co., Ltd, 1993.

[11] J. Li, G. Li, "Earthquake Engineering Introductory Theory," Beijing: Earthquake Press Co., Ltd, 1992.

[12] F. Wu, "Study of Long Span Cable-stayed Bridges Stochastic Seismic Response and Dynamic Reliability," Chengdu: Southwest Jiaotong University, 2008.

\author{
\begin{tabular}{lll}
\hline Received: May 26, 2015 & Revised: July 14, 2015 & Accepted: August 10, 2015
\end{tabular} \\ (C) Fangwen et al.; Licensee Bentham Open.
}

This is an open access article licensed under the terms of the (https://creativecommons.org/licenses/by/4.0/legalcode), which permits unrestricted, noncommercial use, distribution and reproduction in any medium, provided the work is properly cited. 